\title{
Acciones colectivas a favor de los consumidores
}

\author{
Dra. Martha E. Izquierdo Muciño' \\ Universidad Nacional Autónoma de México (UNAM)
}

Recibido: $\quad 03.06 .11$

Aceptado: 05.07 .11

Sumario: Introducción. I. Acciones Colectivas en México. II. Algunos aspectos de Derecho Comparado. III. Reformas al artículo 17 Constitucional. IV. Acciones colectivas a favor de los consumidores. V. Comentarios en torno a la Reforma.

Resumen: La Ley federal de Protección al Consumidor (LFPC) de 1975, que creó a la Procuraduría Federal del Consumidor (PROFECO), había considerado de manera incipiente la forma de representar a los consumidores en forma colectiva ante las autoridades judiciales, lo cierto es que en 30 años de existencia, la PROFECO no había presentado acciones de grupo, lo empezó a hacer hasta 2007 en diversos procedimientos judiciales para que los afectados pudieran recuperar el dinero que habían perdido y fueran indemnizados conforme a la ley. Es por esta situación que la PROFECO ha visto con agrado la modificación al artículo 17 constitucional, pues a través de las acciones colectivas se evitará la presentación de numerosas demandas individuales, con la garantía de una mejor impartición de justicia.

Palabras clave: acciones colectivas, reforma constitucional, consumidores.

Abstract: The federal Law for Consumers Protection (Ley Federal de Proteccion al Consumidor, LFPC) created in 1975 the «Procuraduria Federal del Consumidor (PROFECO)» with the main intention to represent to the consumers in a collective way in front of the Justice authorities. However during its 30 years of creation the PROFECO did not represent any group activities until year 2007 in a diverse of judicial procedures where the victims could recover their lost money and were compensated according the Law. Is for this situation that PROFECO has seen in a gently way the modification of Article No. 17 from the Mexican Constitution where the collective action took place instead individual demands to warrant a better justice for all.

Key words: Collective actions, Constitutional Modification, Consumers.

1 Doctora en Derecho por la Universidad Nacional Autónoma de Mèxico (UNAM), Catedrática e Investigadora de la Universidad Autónoma del Estado de México (UAEM), adscrita al Sistema Nacional de Investigadores (SNI), con publicaciones sobre temas de derechos humanos, derecho social en México y de derecho internacional para la paz. 


\section{Introducción}

México, a diferencia de la mayor parte de las naciones europeas y del continente americano, no contaba con el derecho a las acciones colectivas. Este derecho brinda la oportunidad de que una sola demanda contra una empresa o institución pueda representar a un grupo indeterminado de personas con el fin de evitar actos que les pudieran dañar o bien para exigir la indemnización cuando el acto se ha convertido en un daño, permitiendo de esta manera a los individuos que no cuentan con recursos para iniciar un proceso judicial que sean respetados en juicio por un solo abogado y que la sentencia pueda ser aplicada para todos los afectados.

El ámbito de aplicación de las acciones colectivas comprende la posibilidad de ejercerlas cuando se cometa un fraude contra los consumidores o usuarios, cuando se dañe al medio ambiente, se violen los derechos humanos de un grupo de personas o bien cuando se les afecte en sus derechos de cualquier forma.

Las acciones colectivas garantizan que al ganarse la demanda interpuesta, el grupo sea compensado en sus derechos y al mismo tiempo que las empresas sean disuadidas de volver a cometer este tipo de abusos.

Si bien la Ley federal de Protección al Consumidor (LFPC), de 1975 que creo a la Procuraduría Federal del Consumidor (PROFECO), había considerado de manera incipiente esta forma de representar a los consumidores ante las autoridades judiciales, lo cierto es que en 30 años de existencia, la PROFECO no había presentado acciones de grupo, lo empezó a hacer hasta 2007 en diversos procedimientos judiciales para que los afectados pudieran recuperar el dinero que habían perdido y fueran indemnizados conforme a la ley.

Es por esta situación que la PROFECO ha visto con agrado la modificación al artículo 17 constitucional, pues a través de las acciones colectivas se evitará la presentación de numerosas demandas individuales, con la garantía de una mejor impartición de justicia.

Las acciones colectivas constituyen por tanto un mecanismo de fundamental importancia para la defensa y protección de los intereses y derechos de los miembros de una colectividad o grupo, asimismo constituyen una herramienta fundamental de acceso a la justicia que consolida la defensa ante los tribunales para la defensa de sus derechos colectivos.

Con la reciente aprobación de las acciones colectivas en el sistema jurídico mexicano se habrá de experimentar un cambio rotundo en la forma de impartir justicia, dando un alcance exponencial benéfico en 
los juicios de amparo que se interpongan, toda vez que estos negaron siempre un criterio igualitario a situaciones idénticas si no eran interpuestos directamente por cada uno de los afectados. De esta manera el amparo permitirá pronunciarse en beneficio de una colectividad ò grupo.

\section{Acciones colectivas en México}

No obstante que México es una de las principales economías de América Latina, carecía de un reconocimiento de los intereses y derechos colectivos de sus ciudadanos y de su legitimación activa para hacerlos valer.

En efecto era necesario contar con acciones colectivas para poder acceder a la justicia a través de un procedimiento judicial que permitiese hacer valer los derechos de las personas en forma conjunta y así poder resolver, mediante una sola sentencia, casos de indemnización por daños y perjuicios, de corrección de conductas o bien prevención de actos que pudiesen poner en peligro la seguridad, la salud, la economía, futuro y otros derechos básicos de los individuos.

Para poder demandar ante los tribunales federales la tutela de derechos colectivos o difusos en materia como: protección al consumidor, al medio ambiente, a la competencia económica, a los derechos humanos entre otros más².

Al permitir a los ciudadanos de México y a sus organizaciones sociales, así como a algunas entidades publicas presentar demandas judiciales colectivas para la defensa de intereses y derechos colectivos difusos no reconocidos hasta entonces, se logra un gran avance en la reivindicación del estado de derecho, dado que los procesos individuales eran inviables por sus altos costos, quedando en muchas ocasiones algunos abusos en la impunidad, ya que resultaba imposible que un solo individuo pudiera asumir los costos y los riesgos.

Con la incorporación de este tipo de acciones al sistema procesal mexicano podrá cumplirse con los compromisos internacionales que habían quedado pendientes en diversas materias, tanto de acceso a la

2 http://www.alconsumidor.org/noticias.phtml?id=1030. Javier Corral Jurado: Llegaron las acciones colectivas. Consultado el 7 de abril de 2011. Nuestro país fue pionero en el reconocimiento de los derechos sociales, de segunda generación de los derechos humanos en la Constitución de 1917, pero se había quedado rezagado en el reconocimiento de los derechos «difusos» de tercera generación, que habla sobre las colectividades y grupos de personas como se reconocen ya en varios países de América Latina. 
justicia, como compensaciones efectivas a los consumidores etc., hasta hoy incumplidos.

Los casos que se podrán resolver con una sentencia o medida precautoria en un juicio colectivo son entre otros:

- Prácticas abusivas y discriminatorias de la Banca.

- Prácticas abusivas de las aseguradoras.

- Muertes de menores por negligencia en guarderías públicas o privadas.

— Roaming nacional y redondeo al minuto siguiente de la telefonía celular.

- Venta de productos peligrosos, contaminados, dañinos o tóxicos.

— Publicidad engañosa dirigida a niños.

- Carencia de agua potable en escuelas primarias para el consumo de refrescos.

- Tala masiva de árboles urbanos para destacar anuncios comerciales espectaculares.

- Aislamiento de los pueblos indígenas o rurales del acceso a internet por falta de competencia en banda ancha.

- Falta de facilidades para el acceso al transporte y espacios públicos y privados a los discapacitados.

- Violación a la privacidad y datos personales de los ciudadanos por empresas y gobiernos.

- Abusos a consumidores en suministros, servicios, y contratos de adhesión.

- Daños causados por instituciones de salud sin licencia, o con personal negligente.

- Fraudes al público por empresas de autofinanciamiento y financiamiento no bancario a la vivienda.

- Abusos de casas de empeño y otras formas de crédito comercial.

- Contaminación de aguas o tierras por desechos tóxicos.

- Indemnización a consumidores por los daños sufridos por prácticas monopólicas probadas; entre otras cosas más ${ }^{3}$.

3 http://www. Alconsumidor.org/noticias.phtml?id=987. Por que La reforma La artículo 17 Constitucional? Es la reforma ciudadana mas importante del siglo XXI?: acceso a la justicia colectiva. Alconsumidor. AC Consulta del 27 de marzo 2011. El hecho de incorporar las acciones colectivas a nuestro sistema procesal permitirá a México evitar que se lleven a cabo todas estas situaciones arriba señaladas, como se han dado! así como también cumplir con algunos compromisos internacionales en materia de derechos humanos y de acceso a La justicia entre otros. 
Como puede observarse existía la necesidad de construir nuevas reglas para una mejor convivencia entre ciudadanos, es por ello que se realizo la modificación a nuestro ordenamiento legal, para la protección de las garantías de carácter social y sobre los efectos de las sentencias de amparo. La adhesión al artículo 17 constitucional protege los derechos colectivos y se transforma en principio de relatividad de las sentencias, tratando de definir una nueva categoría de derechos, como el de los consumidores, ambientales, etc.

Cabe mencionar que los intereses comunes han sido llamados por la doctrina como «difusos», cuyo objeto es generar obligaciones del Estado para con la sociedad, pero en virtud de que no se contaba constitucionalmente con la tutela de dichos derechos, existían únicamente dos vías: la jurisdiccional con la interposición de demandas aisladas y la administrativa a través de órganos de la administración pública. ${ }^{4}$

Otras concepciones se refieren los derechos difusos como colectivos e individuales de incidencia colectiva y de intereses individuales homogéneos; en general todas estas acciones regulan las relaciones entre los particulares asumiendo la existencia de intereses afines entre los individuos y procedimientos para su defensa común. ${ }^{5}$

De lo anterior se desprende que los derechos colectivos pueden considerarse como aquellos que pertenecen a los pueblos para ser protegidos de los ataques a sus intereses e identidad como grupo, y las acciones colectivas son aquellas que promueve un representante común (legitimación colectiva), para proteger los intereses del grupo de personas, sujetas a una sentencia que obliga o concede derechos como un todo.

\section{Algunos aspectos de Derecho Comparado}

En materia de derecho comparado podemos afirmar que Estados Unidos definitivamente es un gran referente de estos derechos conocidos como «class actions» que permiten litigios colectivos en todas las

${ }^{4}$ www.senado.gob.mx/ii/sen/content/publicaciones/revista5/3.pdf. Raquel Noyola Zarco: "Perspectivas de Acciones Colectivas», Pluralidad y Consenso n. ${ }^{\circ} 23$. Revista del Instituto de de Investigaciones Legislativas del Senado de la República: Belisario Domínguez. Consulta del 23 de marzo de 2011. Se sabe que algunos grupos de presión: empresariales, políticos etc. Estaban reacios a la reforma dado que entre otras cosas lo que se pretende con ella es proteger los derechos colectivos de los mexicanos frente a los monopolios económicos, lográndole así un mercado mucho mas competitivo.

5 Ibídem. 
materias como accidentes, responsabilidad por productos, cuestiones de competencia económica, derechos de autor, propiedad industrial, derechos de acciones, entre otros.

Pertenecen a un determinado grupo de personas que se encuentran en una situación similar para que puedan ejercitar estos derechos como parte actora.

De tal suerte que la acción que se ejercita por el actor no busca como efecto único garantizar su interés personal tan solo, sino además el de los otros miembros del grupo que se encuentran en las mismas circunstancias.

Su origen se remonta a las Cortes de Equidad del Reino Unido, toda vez que esta acción era propia de todas aquellas personas que eran afectadas por un decreto cuando su número impedía citarlas simultáneamente.

Estas acciones de clase están reguladas fundamentalmente por las denominadas Reglas Federales de Procedimiento Civil, especialmente las reglas 23, 23.1 y 23.2 .

En Europa el Parlamento Europeo emitió una resolución el 13 de marzo de 1987 sobre la compensación a consumidores y en ese mismo año emitió la resolución del Consejo del sobre el acceso de los consumidores a la justicia, para el efecto de que cada uno de los miembros de la Comunidad Europea pudieran establecer la posibilidad de acceso a los consumidores ante sus propias jurisdicciones, por medio de acciones colectivas y de grupo y para que pudieran ser ejercidas por las asociaciones u organizaciones de consumidores con personalidad jurídica, generando con ello la legitimación procesal activa. ${ }^{6}$

En España las primeras acciones colectivas de consumo surgieron en 1998, con el fin de apoyar a las asociaciones de consumidores, favoreciendo su acceso a la justicia, desincentivando los cobros indebidos de menor cuantía, unidad en las resoluciones y restituyendo al consumidor los derechos que le garantizan las normas de consumo.

Lo anterior tuvo como consecuencia la invalidez de los contratos abusivos de servicios, devolución de cantidades ilegítimamente cobradas, multas e indemnizaciones con la finalidad de obligar a la entidad condenada a constituir un fondo de compensación.

En América Latina, Brasil ha sido uno de los países pioneros sobre el tema, ya que desde 1977 legislo sobre esta materia y en los años

6 http://www. Alconsumidor.org/noticias.phtml?id=987. Por que La reforma La artículo 17 Constitucional? Es la reforma ciudadana mas importante del siglo XXl?: acceso a la justicia colectiva. Alconsumidor A.C 
ochenta ya se había elevado a nivel Constitucional al igual que en Argentina y Uruguay.

En efecto el primero de marzo de 1991 entró en vigor el Código de Defensa del Consumidor en Brasil. Dicho dispositivo legal recoge las recomendaciones de la ONU, así como las directrices de la Comunidad Económica Europea, siendo un rasgo principal la sistematización de las normas nacionales sobre relaciones de consumo.

En el ámbito procedimental se hace la diferenciación de las acciones individuales de las colectivas, estas últimas tienen como característica ser resarcitorias de los daños individualmente sufridos por los con consumidores o las víctimas de los productos o servicios, con lo cual se vislumbra una clara alusión a las "class actions for damages» del sistema de common law. ${ }^{7}$

Colombia a su vez ha legislado sobre esta materia así como Chile y Argentina, Perú y Salvador.

En su marco jurídico de 1999, Colombia integró una doctrina que distingue el interés colectivo que pertenece a un grupo organizado e interés difuso (acciones de grupo) lo cual pertenece a una comunidad indeterminada (acciones populares).

De tal suerte que la Constitución Política de Colombia tutela los intereses colectivos relacionados con el patrimonio, el espacio, la seguridad pública, la moral administrativa, el ambiente y la libre competencia económica entre otros más.

\section{Reformas al artículo 17 Constitucional}

En el mes de febrero de 2008, uno de los Senadores del grupo parlamentario del Partido Revolucionario Institucional (PRI), presento la iniciativa de ley para adicionar el párrafo quinto del artículo 17 Constitucional en materia de acciones colectivas, misma que después de su proceso de discusión fue aprobada por el Congreso de la Unión y publicada en el Diario Oficial de la Federación del 29 de julio de 2010.

En la exposición de motivos se planteo la urgente necesidad de establecer acciones que permitiera organizar a los individuos para la defensa de sus derechos en forma grupal o colectiva, toda vez que ante el aumento de relaciones sociales y las interrelaciones entre los diver-

7 www.senado.gob.mx/ii/sen/content/publicaciones/revista5/3.pdf. Raquel Noyola Zarco: "Perspectivas de Acciones Colectivas», Pluralidad y Consenso n. ${ }^{\circ} 23$. Revista del Instituto de de Investigaciones Legislativas del Senado de la República: Belisario Domínguez. 
sos sectores de la sociedad, hacían cada vez mas difícil este tipo de defensa ${ }^{8}$.

Las acciones colectivas se enfocaron a tres campos concretamente: la protección al consumidor, a los usuarios de servicios financieros y al medio ambiente, toda vez que en estas tres esferas se habían constituido mayormente los reclamos de la sociedad cuyas demandas no alcanzaban a ser procesadas de forma colectiva y tanto los Jueces o Tribunales habían dado siempre una respuesta individual, de esta manera se canalizaron las miles de demandas contra diversos sectores de la administración publica tales como, la Procuraduría Federal del Consumidor (PROFECO), la Comisión Nacional para la Protección y Defensa al Usuario de Servicios Financieros (CONDUSEF), y la Procuraduría Federal de Protección al Ambiente (PROFEPA).

El artículo 17 de Constitucional quedó de la siguiente manera:

Artículo 17. Ninguna persona podrá hacerse justicia por sí misma, ni ejercer violencia para reclamar su derecho.

Toda persona tiene derecho a que se le administre justicia por tribunales que estarán expeditos para impartirla en los plazos y términos que fijen las leyes, emitiendo sus resoluciones de manera pronta, completa e imparcial. Su servicio será gratuito, quedando, en consecuencia, prohibidas las costas judiciales.

El Congreso de la Unión expedirá las leyes que regulen las acciones colectivas. Tales leyes determinarán las materias de aplicación, los procedimientos judiciales y los mecanismos de reparación del daño. Los jueces federales conocerán de forma exclusiva sobre estos procedimientos y mecanismos.

Las leyes preverán mecanismos alternativos de solución de controversias. En la materia penal regularán su aplicación, asegurarán la reparación del daño y establecerán los casos en los que se requerirá supervisión judicial.

Las sentencias que pongan fin a los procedimientos orales deberán ser explicadas en audiencia pública previa citación de las partes.

Las leyes federales y locales establecerán los medios necesarios para que se garantice la independencia de los tribunales y la plena ejecución de sus resoluciones.

8 www.alconsumidor.org. Luis Alberto Amado Castro: Salud mental discriminación y aseguradoras. Las acciones colectivas como catalizador de mejores prácticas. El 29 de de julio de 2010 fue publicado en el Diario Oficial de la Federación el «DECRETO» por el que se adicionaba un párrafo al artículo 17 de la Constitución Políticas de los Estados Unidos Mexicanos que tuvo por objeto la protección de los derechos que le asisten a una colectividad determinada o a grupo de personas que cuentan con elementos comunes y que permiten su litigio en forma colectiva. 
La Federación, los Estados y el Distrito Federal garantizarán la existencia de un servicio de defensoría pública de calidad para la población y asegurarán las condiciones para un servicio profesional de carrera para los defensores. Las percepciones de los defensores no podrán ser inferiores a las que correspondan a los agentes del Ministerio Público. civil.

Nadie puede ser aprisionado por deudas de carácter puramente

En la propia exposición de motivos de la reforma constitucional quedó establecido que los derechos colectivos comprenden a:

- Derechos difusos.

- Derechos colectivos en sentido estricto.

- Derechos individuales de incidencia colectiva.

Los dos primeros se consideran como derechos e intereses supraindividuales de naturaleza indivisible, de los que son titulares una colectividad indeterminada (derechos difusos) o determinada (colectivos en sentido estricto), cuyos miembros se encuentran vinculados por circunstancias especificas.

En cambio los derechos individuales de incidencia colectiva, son aquellos de carácter individual y divisible que por determinadas circunstancias permiten su protección y defensa en forma colectiva. Estos últimos determinados por circunstancias tanto de hecho como de derecho (colectivos en sentido estricto, e individuales de incidencia colectiva) aquí es en donde se concentra concretamente la iniciativa de ley en mención, al establecer que los costos hacen que no sea económicamente viable la defensa de dichos derechos.

Aclarando que no significaba que no estuviesen siendo vulnerados sus derechos, sino que se evidenciaba una violación al sistema jurídico por cuestiones de incosteabilidad en tiempo y en dinero?

De tal suerte que lo que se buscaba era regular de manera ordenada las condiciones para agrupar a todas aquellas personas cuyos derechos hubiesen sido vulnerados y lograr una adecuada defensa para la protección de sus intereses.

Con la adición del párrafo tercero del artículo 17 Constitucional se otorga al Congreso de la Unión amplias facultades que habrán de regularse por los siguientes parámetros:

- Determinar las materias de aplicación.

— Establecer los procedimientos judiciales.

9 www.alconsumidor.org. Luis Alberto Amado Castro: Salud mental discriminación y aseguradoras. Las acciones colectivas como catalizador de mejores prácticas. 
- Indicar los mecanismos de reparación del daño.

- Disponer que los jueces federales conocerán de forma exclusiva sobre estos procedimientos y mecanismos.

Amado Castro advirtió que las acciones colectivas sobre derechos difusos deben quedar debidamente reguladas lo antes posible, ya que de lo contrario podrían retrasar aun más la realización de proyectos importantes, por lo que se hace necesario establecer los límites de responsabilidad para que las soluciones sean realmente ágiles. ${ }^{10}$

Actualmente han sido presentadas varias iniciativas para dar cumplimiento al mandato constitucional que autoriza que el Congreso de la Unión debe realizar las adecuaciones legislativas que correspondan en un plazo máximo de un año a partir de la fecha de su expedición. (artículo primero transitorio del Decreto del 29 de julio de 2010) .

\section{Acciones colectivas en favor de los consumidores}

En el caso de las acciones colectivas en México, a favor de los consumidores debemos mencionar que anteriormente la protección al consumidor quedaba conferida exclusivamente a la Procuraduría Federal del Consumidor (PROFECO) y si bien a partir de 1992 conforme al artículo 26 de la Ley Federal de Protección al Consumidor se autorizaba que se podrá ejercer ante los tribunales competentes acciones de grupo en representación de los consumidores, también lo es que nunca se estableció un procedimiento especial o ágil, para el efecto de que dichos tribunales estuviesen en posibilidad de resolver los casos presentados por PROFECO en forma colectiva, así como tampoco tuvieron los Jueces la facultad de oír y resolver los casos colectivos con un procedimiento especial.

De hecho fueron escasas las acciones colectivas que se llevaron a cabo y que lejos de poder encontrar una respuesta ágil y sencilla a sus demandas, PROFECO enfrento serias resistencias de los Jueces, por carecer de competencia.

Por otra parte México es el segundo país latinoamericano con una Ley Federal de Protección al Consumidor y el Primero en crear una Procuraduría, por tanto puede decirse que la experiencia mexicana es importante, en especial para los demás países en Latinoamérica que empiezan a trabajar en la protección de los derechos de los consumidores.

10 Ibídem. 
En efecto, a partir de 1976 contamos con la Ley Federal de Protección al Consumidor creándose en consecuencia un organismo especializado de procuración de justicia en la esfera del consumo.

Nacen así el Instituto Nacional del Consumidor y la Procuraduría Federal del Consumidor, esta última como organismo descentralizado de servicio social, personalidad jurídica y patrimonio propio, con funciones de autoridad administrativa, encargada de promover y proteger los intereses del público consumidor ${ }^{11}$.

Dicha institución contaba ya en 1982 con 32 oficinas en las principales ciudades del país.

Cabe mencionar que la Ley Federal de Protección al Consumidor ha sido objeto de diversas reformas:

- A partir del 7 de enero de 1982, el artículo 29 Bis permite a PROFECO regular los sistemas de comercialización, utilizados en el mercado nacional.

- Desde el 7 de febrero de 1985, la Ley regula la competencia, naturaleza jurídica y atribuciones de PROFECO; incluye nuevas definiciones, denominaciones e información de bienes y servicios, facultades que entonces tenía la Secretaría de Comercio y Fomento Industrial, al referirse a la información comercial que ostentan productos o etiquetas, ventas al consumidor, promociones, etc.

- El 4 de enero de 1989, algunos artículos de la Ley confieren a PROFECO la facultad de sancionar y recibir denuncias por violaciones a los precios.

- El 6 de febrero de 1991, el Reglamento de la propia Ley establece las bases de organización y funcionamiento de PROFECO; en consecuencia, fortalece los mecanismos de defensa de los derechos e intereses de la población consumidora.

—El 7 de febrero de 1991 el acceso a los servicios es más fácil con la alineación y adscripción orgánica de las unidades administrativas toda vez que existe una mejor organización y distribución del trabajo.

- El 24 de diciembre de 1992, se fusionan dos instituciones: INCO (Instituto Nacional del Consumidor) y PROFECO para integrar nuevas funciones como el trámite y conciliación de quejas y denuncias, la emisión de resoluciones administrativas, registro de contratos de adhesión, protección técnico-jurídica a los consumidores, verificación y vigilancia de Normas Oficiales Mexicanas, pesas y

11 http:// revista del consumidor.gob.mx/?page_id=297. Revista del consumidor, en línea. Consulta de 17 de abril 2011 
medidas exactas, supervisión de precios oficialmente autorizados, acciones de grupo, publicidad correctiva, organización y capacitación de los consumidores y la educación para el consumo.

— En 1994, la Ley Federal de Protección al Consumidor vuelve a ser objeto de ajuste al adicionársele diversas disposiciones. Se reforma la Procuraduría y se dispone que las delegaciones cuenten con facultades amplias y suficientes para hacer expeditos los programas de trabajo desconcentrados ${ }^{12}$.

No obstante lo anterior se observa que desde la creación de la Ley Federal de Protección al Consumidor de 1976 (que creo a su vez a PROFECO) la forma de representar a consumidores ante las autoridades judiciales resultaba incipiente ya que, en 30 años de existencia, PROFECO no había presentado acciones de grupo, esto se hizo hasta el año 2007 en contra de Air Madrid y Líneas Aéreas Azteca y en 2008 loa PROFECO presento una tercera acción de grupo en contra de una empresa inmobiliaria en la Ciudad de Chihuahua, Chihuahua, y recientemente ha interpuesto acciones de grupo contra Aero California S.A. de C.V. y del Grupo AVIACSA.

De hecho podemos afirmar que a nivel internacional también existen normas jurídicas que defienden a los consumidores como es: la Carta Europea de Protección de los Consumidores, publicada en 1973, que reconoció el derecho de los consumidores a organizarse en asociaciones y a ser representados.

Posteriormente se creo el Programa Preliminar para la Comunidad Económica Europea, además en la Organización de Naciones Unidas se establecieron las directrices para la Protección al Consumidor en abril de $1985^{13}$.

Pues bien, bajo estas bases se ha ido integrando el marco normativo de los derechos en México, luego entonces podemos afirmar que en nuestro país los consumidores están protegidos por la Ley Federal de Protección al Consumidor, bajo los siguientes principios:

- Derecho a la protección de la salud y la seguridad.

- Derecho a la educación y formación en materia de consumo.

- Derecho a la información.

12 Ibídem.

13 http/www.El poder del consumidor.org/los_derechos_del_consumidor.html El poder del consumidor. Los derechos del consumidor. Consulta de 28 de marzo de 2011. Sin embargo como podrá observarse, realmente fue Estados Unidos en época de la «gran depresión» cuando surgieron las primeras manifestaciones de los consumidores contra los especuladores y acaparadores de precios. 
- Derecho a la etapa de prevención y reparación de daños.

- Derecho de representación, consulta y participación.

- Derecho a la protección de intereses económicos y sociales.

- Derecho a la protección ante cualquier situación que cause indefensión.

Como puede observarse en esta ley la PROFECO reconoce al consumidor siete derechos: a la información, a elegir, a no ser discriminado, a la protección, a la educación, a la seguridad y calidad, y a la compensación ${ }^{14}$.

- El derecho a la protección de la salud y la seguridad significa que ningún producto o actividad o servicio puesto en el mercado tendrá riesgo para la salud o seguridad del consumidor o usuario y que en caso de que existen artículos que sin ser peligrosos pueden no ser recomendables para algunos usuarios, es obligatorio informar en el etiquetado de los riesgos, consecuencias y como evitarlos.

- Derecho a la educación y formación en materia de consumo menciona que es necesario formar a la población para adquirir hábitos saludables a fin de que puedan acceder con mayor libertad a los bienes del mercado, utilizarlos de manera más racional y evitar riesgos.

- Derecho a la información_este resulta ser otro de los derechos básicos de los consumidores, que complementa los demás en virtud de que el derecho que tenemos todos los consumidores a salir y conocer suficientemente las características reales de los productos y servicios que nos ofrecen, además que el conocimiento debe ser en forma directa e inmediata.

La ley determina que los fabricantes están obligados a indicar el nombre genérico, marca comercial, naturaleza del producto, composición, categoría, cantidad, precio de venta al público, fecha de caducidad e instrucciones de uso o consumo.

- Derecho a la prevención y reparación de daños significa que en el caso de haber sido victima de un engaño, fraude o similar, tiene derecho a recibir una compensación por ello. Así como todos los consumidores tienen derecho a recibir una indemnización por los daños y perjuicios ocasionados. Con excepción de aquellos casos en que el daño sea ocasionado por negligencia, descuido o mala utilización por parte del usuario.

14 lbídem. 
- Derecho a la representación, consulta y participación parte de la idea de que es casi imposible que cada consumidor pueda dar su opinión de manera individual ante cualquier conflicto que afecte al colectivo, por eso este derecho se ejerce de manera indirecta a través de las asociaciones de consumidores, toda vez que contribuyen a fortalecer los derechos de los ciudadanos.

- Derecho a la protección de intereses económicos y sociales este quizás sea el derecho mas conocido y mas importante para el consumidor toda vez que es un derecho que le permite exigir la reparación de los daños que haya sufrido como consecuencia de la adquisición de bienes o prestación de servicios, pero garantizando que la publicidad, promociones y sorteos y ofertas no engañen al consumidor.

- Derecho a la protección ante cualquier situación que cause indefensión al consumidor significa que en virtud de que en muchas ocasiones el consumidor es la parte mas débil de la relación jurídica que se establece entre el y el comprador, la ley establece unas acciones que deberán adoptar los poderes públicos que habrán de permitir a los consumidores estar en condiciones de mayor igualdad como pueden ser: campañas de orientación al consumo, campañas de control de calidad, etc. ${ }^{15}$.

Estos derechos garantizan que ningún vendedor podrá imponer renuncia alguna por parte de los ciudadanos a los derechos de la salud, seguridad, información, reparación de daño etc. etc.

\section{Comentarios en torno a la reforma constitucional}

El procedimiento para reformar la Constitución Mexicana es similar al que prevé la Constitución de los Estados Unidos de Norteamérica, no obstante cuenta con algunas diferencias. Al respecto Miguel Carbonel sostiene que en primer termino la Constitución mexicana dispone de dos procedimientos de reforma uno que podría denominarse súper agravado y que sirve tan solo para modificar el capitulo territorial de la Constitución y otro fundamentalmente agravado que es el que se utiliza normalmente para cambiar las de-

15 http://www.eurosur.org/CONSUVEC/contenidos/informac/Derechos/N_Derechos. htm Cuales son los derechos del consumidor y usuarios? Consulta de 28 de marzo de 2011. 
más partes del texto constitucional el cual resulta muy flexible en la practica ${ }^{16}$.

El primero de ellos se encuentra regulado por el artículo 73, fracción III, y el segundo por el artículo 135 constitucional.

En consecuencia y conforme la fracción citada del artículo 73 el Congreso de la Unión tiene facultad de admitir nuevos Estados a la Unión Federal, el listado de entidades que conforman a la federación se en encuentra en lo dispuesto por el artículo 43 Constitucional y la forma en que el Congreso puede ejercer esta facultad que le otorga el citado artículo 73 requiere considerar los siguientes requisitos:

Articulo 73. El congreso tiene facultad:

I. Para admitir nuevos estados a la unión federal;

II. Derogada;

III. Para formar nuevos estados dentro de los limites de los existentes, siendo necesario al efecto:

1. Que la fracción o fracciones que pidan erigirse en estados, cuenten con una población de ciento veinte mil habitantes, por lo menos.

2. Que se compruebe ante el congreso que tienen los elementos bastantes para proveer a su existencia política.

3. Que sean oídas las legislaturas de los estados de cuyo territorio se trate, sobre la conveniencia o inconveniencia de la erección del nuevo estado, quedando obligadas a dar su informe dentro de seis meses, contados desde el día en que se les remita la comunicación respectiva.

4. Que igualmente se oiga al ejecutivo de la federación, el cual enviara su informe dentro de siete días contados desde la fecha en que le sea pedido.

5. Que sea votada la erección del nuevo estado por dos terceras partes de los diputados y senadores presentes en sus respectivas cámaras.

6. Que la resolución del congreso sea ratificada por la mayoría de las legislaturas de los estados, previo examen de la copia del expediente, siempre que hayan dado su consentimiento las legislaturas de los estados de cuyo territorio se trate.

7. Si las legislaturas de los estados de cuyo territorio se trate no hubieren dado su consentimiento, la ratificación de

16 www.juridicas UNAM.MX. Carbonel, Miguel: Notas sobre la reforma constitucional en México. Biblioteca Jurídica Virtual del Instituto de Investigaciones jurídicas de la UNAM. Consulta de 28 de febrero de 2011 
que habla la fracción anterior, deberá ser hecha por las dos terceras partes del total de legislaturas de los demás estados.

IV. Para arreglar definitivamente los limites de los Estados, determinando las diferencias que entre ellos se susciten sobre las demarcaciones de sus respectivos territorios, menos cuando esas diferencias tengan un carácter contencioso.

V. Para cambiar la residencia de los supremos poderes de la federación;

VI. Derogada; ...

Por su parte el artículo 135 que es el único que integra el titulo octavo y que lleva por titulo «de las Reformas a la Constitución» dispone lo siguiente:

La presente Constitución puede ser adicionada o reformada. Para que las adiciones o reformas lleguen a ser parte de la misma, se requiere que el Congreso de la Unión, por el voto de las dos terceras partes de los individuos presentes, acuerde las reformas o adiciones, y que éstas sean aprobadas por la mayoría de las legislaturas de los estados $^{17}$.

El Congreso de la Unión o la Comisión Permanente, en su caso, harán el cómputo de los votos de las legislaturas y la declaración de haber sido aprobadas las adiciones o reformas.

Sin embargo, como lo menciona el citado autor Miguel Carbonel hasta la fecha ni la doctrina ni la jurisprudencia, ni mucho menos en la práctica se ha encontrado la diferencia entre adicionar y reformar que se utiliza en el citado artículo 135, además de que entran las siguientes cuestiones:

a) No señala qué sujetos tienen la facultad de presentar iniciativas de reforma constitucional.

b) No se describe la tramitación de las iniciativas, aunque se sostiene que dichas iniciativas pueden ser presentadas por los integrantes del congreso de la Unión (Cámara de Diputados y Senadores), legisladores de los Congresos estatales y por el Presidente de la República.

17 Carbonel Miguel (coordinador) (2004): Constituciòn Política de los Estados Unidos Mexicanos Comentada. Editorial Porrua y Universidad Nacional Autônoma de México.México, p.150. 
c) Por el carácter rígido del texto constitucional, el artículo 135 establece que la votación necesaria para aprobar una modificación a la Carta Magna es de dos terceras partes de los individuos presentes. Lo cual a primera vista parecer muy alta, pero en realidad no lo es ya que el límite que pudiera estar en una sesión es $50 \%$ más uno (requisito indispensable señalado en la propia Constitución art. 63).

d) El artículo 135 de la Constitución no señala si la eventual aprobación por parte de las legislaturas locales debe ser por alguna mayoría calificada.

e) No señala si en el procedimiento de reforma debe intervenir el órgano legislativo del Distrito Federal que es la Asamblea Legislativa. Lo cual a su juicio es una omisión incomprensible.

f) Es necesario que una vez que se hayan reunido los votos aprobatorios de las legislaturas de los estados se declarare que la reforma constitucional ha sido aprobada.

g) Que una vez que la reforma haya sido aprobada el Congreso de la Unión procede a ordenar su publicación en el Diario Oficial de la Federación, así como en los periódicos y gacetas oficiales de las entidades federativas.

Además sostiene el citado autor que en los últimos años concretamente entre la década de los 90's; la reforma Constitucional en México ha experimentado tres procesos de cambios como son:

a) Hasta hace poco, la doctrina no tenía claro que los procedimientos de reforma constitucionales pudieran ser controlados por el Poder Judicial Federal.

b) Otro cambio que se observa es la posibilidad no jurídica sino política de aprobar reformas constitucionales.

c) Y finalmente sobre el papel cada vez más relevante que han tomado las legislaturas locales ${ }^{18}$.

De hecho nuestra constitución en 85 años de vigencia. Ha alcanzado mas de 600 modificaciones y este número tan elevado de modificaciones constitucionales pone en entredicho el principio de supremacía formal de la Constitución pues al parecer se ha desvanecido el procedimiento dificultado que para sus reformas tienen las normas fundamentales no habiéndose operado en la nuestra como una autentica protección especial. 
Lo anterior obliga a plantearnos seriamente la necesidad de cambiar nuestro sistema de reformas constitucionales por uno que sea menos sensible a los factores puramente políticos, toda vez que la supremacía formal de la Constitución es un principio fundamental de la teoría política contemporánea ${ }^{19}$.

Respecto a la reforma al artículo 17 Constitucional y en lo relativo a las acciones colectivas o de grupo, puede decirse que a juicio de algunos expertos aun resulta limitada:

- Resulta limitada puesto que la protección a la vida y a la salud, no se cumplen desde el momento en que seguimos consumiendo miles de sustancias químicas añadidas a los alimentos procesados sin ser informados acerca de sus riesgos, y mientras desconozcamos la manera como contribuimos mediante nuestro consumo al deterioro del entorno, del planeta, de nuestra salud y de nuestra vida.

- Resulta limitada porque no puede ejercer plenamente el derecho a la educación y la información y porque en lo relacionado con la reparación de daño provocado por el consumo de productos o servicios, no podrá cumplirse mientras no sea cubierta por los propios proveedores ya que los costos los asumen por ahora los propios afectados o indirectamente los contribuyentes, cuando es el Estado el que asume la responsabilidad de la reparación.

- Resulta limitada mientras no se eliminen los productos «chatarra» de las cooperativas escolares de todo el país que afectan a 25 millones de niños en edad escolar pese al esfuerzo de nuestras autoridades, frente al privilegio de los intereses de grupos empresariales entre otras cosas mas. ${ }^{20}$

De tal suerte que resultaba importante que se reforzaran realmente los derechos de los consumidores y se ampliasen hacia el reconocimiento de nuevos derechos que aun no habían sido reconocidos en nuestras leyes mexicanas.

Con la reciente aprobación de las acciones colectivas en el sistema jurídico mexicano habrá de experimentarse un cambio trascendente en

19 Carbonel Miguel.(coordinador): ob. cit., p.156.

20 http://www. El poder Del consumidor.org/los_derechos_del_consumidor.html. Los derechos del consumidor. Es necesario que en las cooperativas escolares tanto maestros como alumnos vigilen el cumplimiento de los lineamientos establecidos para la venta de alimentos y bebidas y se evite la venta de la «comida chatarra» o de lo contrario les sea retirada la concesión, toda vez que la población mexicana tiene ya el mayor consumo de calorías en el mundo con el expendio de este tipo de alimentos. 
la forma de la resolución de conflictos, logrando así un alcance excepcional y benéfico dentro del juicio de amparo a favor de los consumidores. Sin embargo es necesario aclarar todavía algunas inquietudes como son:

- Los temas a la acción y defensa colectiva: Para mucha gente resulta inadmisible que las acciones colectivas sólo se reduzcan a los consumidores, servicios financieros y medio ambiente, toda vez que quedan fuera muchos otros aspectos como son los derechos humanos, asuntos laborales, derechos de los ciudadanos, entre otros más, por lo tanto se considera que esta ley es discriminatoria.

Por otra parte el haber dispuesto que las acciones colectivas habrán de ser en materia exclusivamente federal impide que cualquier entidad federativa, puedan legislar en dichos rubros.

- Legitimidad de las acciones colectivas: El hecho de que para emprender acciones colectivas se deba constreñir a instituciones como la PROFECO, CONDUSEF y la PROCURADURÍA DEL MEDIO AMBIENTE es negar el derecho a otros grupos sociales para poder ejercer esta acción.

- La reparación de daño: Lo más importante de la acción colectiva es el pago de la indemnización y la reparación del daño, que es la esencia en si de este tipo de acciones precisamente de disuadir el comportamiento abusivo y el daño que provocan las empresas y las instituciones gubernamentales.

Toda vez que la sanción no debe reducirse exclusivamente al pago de la indemnización y permitir que continúe la conducta arbitraria dañando el desarrollo sustentable y la propia economía de la población.

- Requisitos en la presentación de la demanda colectiva: El hecho de que exista en la ley reglamentaría una serie de requisitos en términos del tiempo, de membrecía, de representatividad, etc. pueden hacer sumamente difícil que los diferentes grupos que requieren estas acciones se vena impedidos para poder ejercerlos.

- De los sujetos legitimados: Otro punto por aclarar en la ley secundaria es definir quienes serán los sujetos para ejercer la demanda, efectos y alcances de la sentencia, concepto de "daño» para cuantificación del monto a pagar, la opción de permanecer o salir del grupo demandante sin perder el derecho al reclamo etc. ${ }^{21}$

21 http://www.consumidores.org.mxpublican_reforma_de_acciones_colectivas.html. Víctor Fuentes (periódico Reforma): Consulta de 14 de marzo de 2011. 
No obstante lo anterior, podemos afirmar que las acciones colectivas, serán un gran avance en la reforma del Estado pues el hecho de incorporarlos a nuestro sistema procesal permitirá a México cumplir con los compromisos internacionales aun no cumplidos, así como sus compromisos para legislar en materia de compensaciones efectivas a las comunidades, asumidas por nuestro país como miembro de la OCDE, tarea que queda aun pendiente.

En definitiva el hecho de permitir a los ciudadanos de México presentar demandas judiciales colectivas para la defensa de sus intereses y derechos colectivos y difusos, será un catalizador en la reivindicación del estado de Derecho.

\section{Bibliografía y fuentes}

http://www.alconsumidor.org/noticias.phtml?id=1030. Javier Corral Jurado: Llegaron las acciones colectivas. Consulta del 7 de abril de 2011

http://www.alconsumidor.org/noticias. phtml?id=987. Por que La reforma La artículo 17 Constitucional es la reforma ciudadana mas importante del siglo Xxl?: acceso a la justicia colectiva. Alconsumidor. AC Consulta del 27 de marzo 2011.

www.senado.gob.mx/ii/sen/content/publicaciones/revista5/3.pdf. Raquel Noyola Zarco: "Perspectivas de acciones colectivas», Pluralidad y Consenso n. ${ }^{\circ} 23$. Revista del Instituto de de Investigaciones Legislativa. Senado de la República: Belisario Domínguez. Consulta del 23 de marzo de 2011.

www.alconsumidor.org. Luis Alberto Amado Castro: Salud mental discriminación y aseguradoras. Las acciones colectivas como catalizador de mejores prácticas. Consulta de 10 de marzo 2011.

http:// revista del consumidor.gob.mx/?page_id=297. "Qué es Profeco?», Revista del consumidor, en línea. Consulta de 17 de abril 2011.

http://www.eurosur.org/CONSUVEC/contenidos/informac/Derechos/N_ Derechos.htm. ¿Cuáles son los derechos del consumidor y usuarios? Consulta de 28 de marzo de 2011.

www.juridicas UNAM.MX. Carbonel Miguel: Notas sobre la reforma constitucional en México. Biblioteca Jurídica Virtual del Instituto de Investigaciones jurídicas de la UNAM. Consulta de 28 de febrero de 2011.

Carbonel Miguel (coordinador) (2004): Constitución política de los Estados Unidos mexicanos Comentada. Editorial Porrua y Universidad Nacional Autónoma de México. México, p. 150.

http://www. elpoderdelconsumidor.org/los_derechos_del_consumidor.html. El poder del consumidor, los derechos del consumidor. Consulta del 28 de marzo de 2011.

http://www.consumidores.org.mxpublican_reforma_de_acciones_colectivas. html. por los derechos del consumidor y contra los monopolios. Consulta de 14 de marzo de 2011. 